\title{
New Telematic Technologies for Remote Creation, Rehearsal and Performance of Choreographic Work
}

DANIEL STRUTT (1)

ANDREAS SCHLEGEL

NEAL COGHLAN

CLEMENCE DEBAIG

YOUHONG 'FRIENDRED' PENG

*Author affiliations can be found in the back matter of this article

\author{
SPECIAL \\ COLLECTION:
}

SPECIAL ISSUE OF

ILLUMINATED VIDEOS

VIDEO ARTICLE

(3) 1

Open Library of Humanities



CORRESPONDING AUTHOR:

\section{Daniel Strutt}

Goldsmiths, University of

London, UK

daniel.strutt@gold.ac.uk

\section{KEYWORDS:}

motion-capture; telematic; performance; dance; choreography; virtual

TO CITE THIS ARTICLE: Strutt, D, Schlegel, A, Coghlan, N, Debaig, C and 'Friendred' Peng, Y. 2021. New Telematic Technologies for Remote Creation, Rehearsal and Performance of Choreographic Work. Journal of Embodied Research, 4(2): 4 (14:57). DOI: https://doi. org/10.16995/jer.82 
Available for download here: https://doi.org/10.16995/jer.82.s1.

\section{STILLS FROM THE VIDEO ARTICLE}
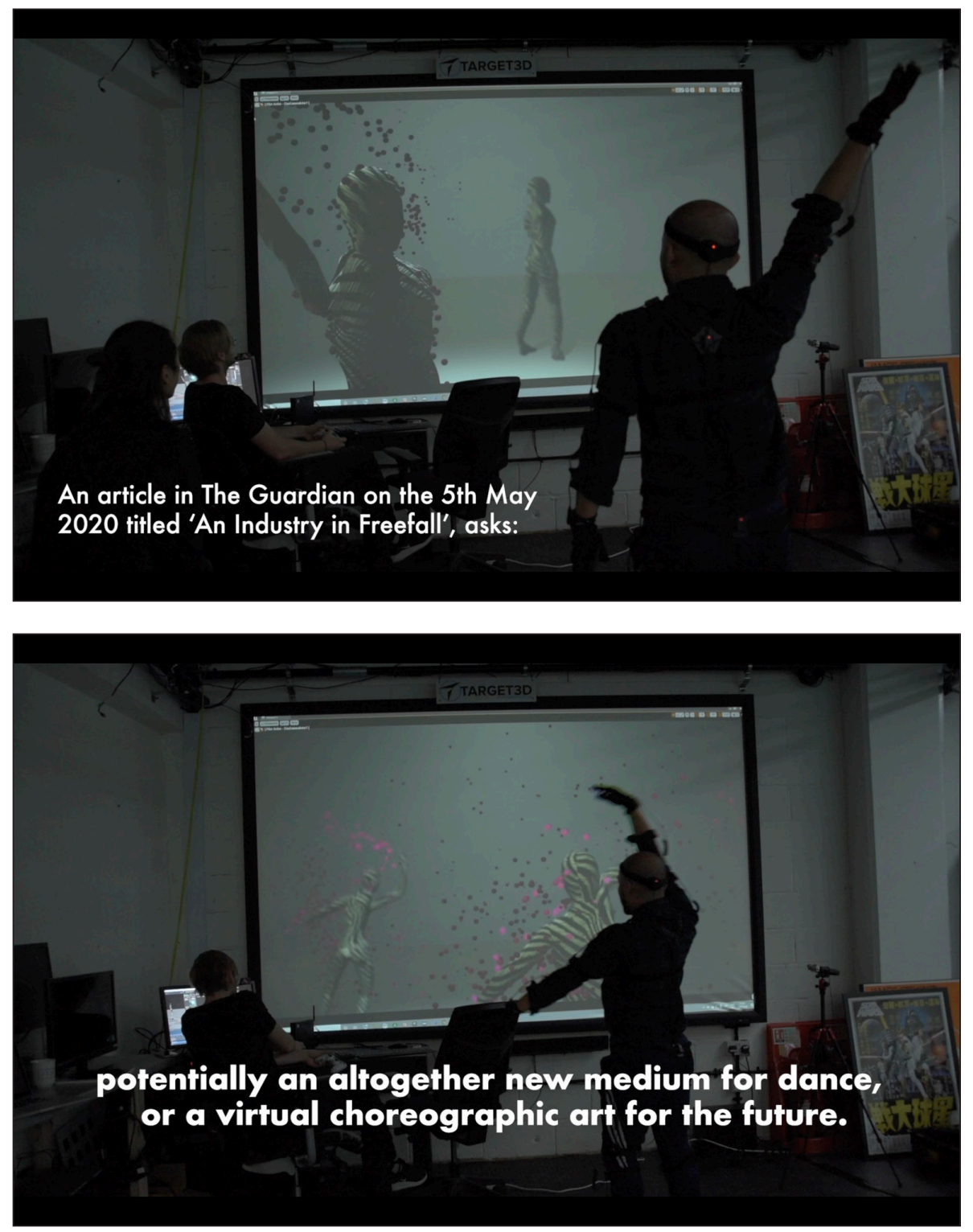

\section{In his view, the} juxtapositions need to be meaningful rather thanseparated and arbitrary.' 


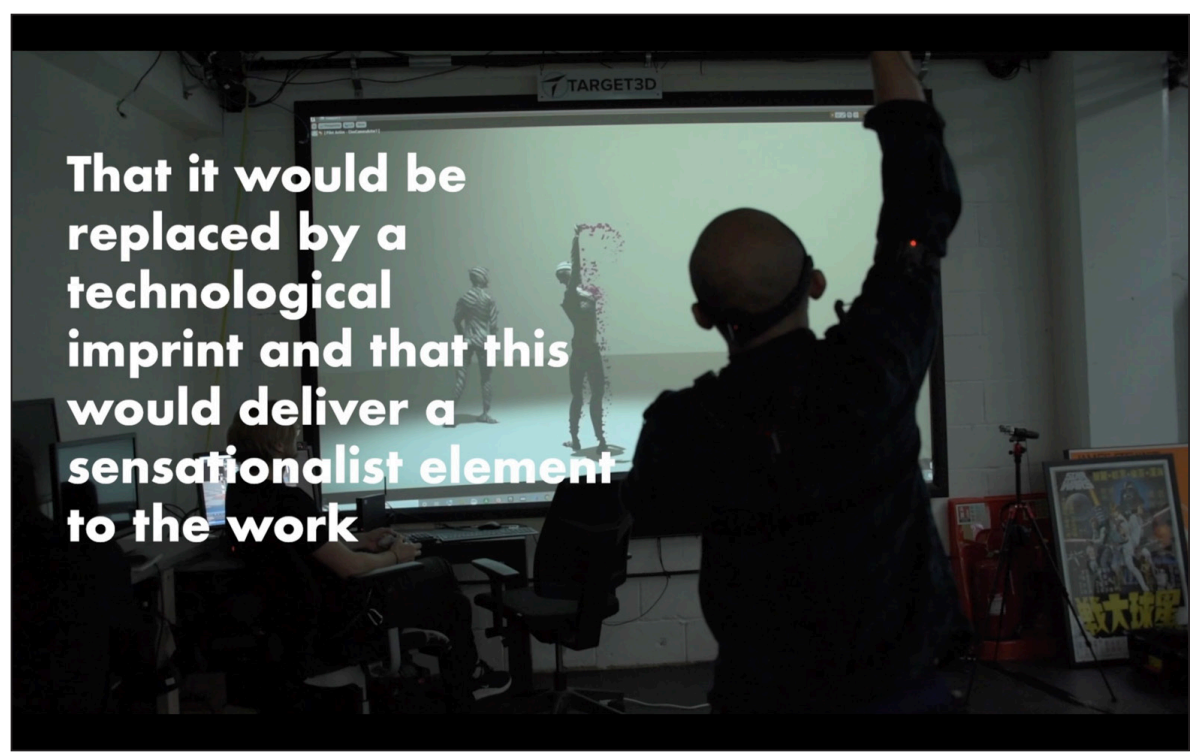

\section{VIDEO ARTICLE TRANSCRIPT}

[Note: This is a transcript of a video article. Individual elements from the transcript, such as metadata and reference lists, may appear more than once in the document, in order to be properly read and accessed by automated systems. The transcript can be used as a placeholder or reference when it is not possible to embed the actual video, which can be found by following the DOI.]

[00:10]

\section{NEW TELEMATIC TECHNOLOGIES \\ FOR REMOTE CREATION, \\ REHEARSAL \\ AND PERFORMANCE \\ OF CHOREOGRAPHIC WORK.}

A Goldsmiths based AHRC funded project within the 'Tackling the Impact of COVID-19' UKRI call.

In collaboration with LASALLE College of the Arts Singapore, Akram Khan Dance Company, and Target3D.

An article in The Guardian of the 5th May 2020 titled 'An Industry in Freefall', asks:

'With tours cancelled and rehearsal rooms closed, what's the future for dance?'

(Bakare, The Guardian).

Within this moment of crisis, we offer an interdisciplinary collaborative project;...

... to research the potential application of new forms of...

inertial sensor

wireless

and

markerless

motion

capture

in the

physically-distanced

creation,

rehearsal,

teaching

and performance

of choreographic dance work 
There is, currently, a lively discussion about possibilities for future arts projects and the forms of revenue and income it might generate, as...

virtual festivals,

digital art events,

and interactive media

...move to the centre

of debate about a

'culture in quarantine'.

But how does dance fit into this?...

.... when the practice of dance

is inherently about close bodily

contact as fundamental to the

discipline?

In this experimental test session, two dancers, one in London, and one in Singapore, are dancing together, but virtually, each wearing an inertial sensor motion capture system.

Live and pre-captured dance data was streamed from a dancer in similar studio space in LASALLE college in Singapore, some 6700 miles away, with barely noticeable delay or latency.

This is achieved by sending motion capture data as BVH formatted binary data over UDP, or if preferred, as OSC messages, in both cases over a p2p network connection.

In addition, the data can be distributed via WebSocket so that it can be visualized and viewed in a browser.

In future versions, a dedicated cloud server will be used to distribute and share data across multiple client machines.

Although with occasional technical glitches, including magnetic interference with the suit, this raw footage operates as proof of concept,...

and a suggestion of what is to come in the next iteration of our research.

We position this research practice within a historical and theoretical problematic of...

networked

or 'distributed performance'

and of telepresence,

telematics,

and virtuality in dance practice.

(Birringer, J. Performance, Technology, \& Science. New York: PAJ. 2008)

It is not about recreating the live experience - of 'being there' - but rather finding forms of...

meaningful

connection,

engaged

interest

and attention

in a digital medium

which is decisively and

qualitatively different.

We consider the ways in which forms of connection,...

between performer and performer,

and between performer and audience,

while limited in terms of actual somatic immersion (for instance the sense of touch, smell, temperature, spatial audio etc.),...

... can be articulated differently, or even enhanced, in virtual and technologically augmented modes,... 
playing to the strengths and affordances of real time generative games engines and immersive interfaces.

This is not only about solutions to the problems of physical distancing...

... that choreographers and dancers might face in the immediate future, but also offers a futurist vision:

potentially an altogether new medium for dance, or a virtual choreographic art for the future.

'Certain forms of digital technology provide a framework for choreography

which opens up new modes of practice, and new ways of thinking in and through dance.

Amongst these are those forms of digital media which allow for real-time interactivity.

These may prove to be a new medium, not merely a new tool, for choreography.'

(Rubidge, S. "Digital Technology in Choreography: Issues and Implications." Given at the 17th Annual Symposium of the Dance Society of Korea, Seoul, Korea, November 6th 2002)

While live telematic performance has been around since the 1980s, it seems a history of struggle with the inherent technical difficulties of tele-communication -

delay,

latency,

and glitch

on one hand..

and a palpable frustration at the lack of the aesthetic advancement, or emotional connection that such projects aspire to.

The unattained ideal remains in 2020 to have not only a real-time networked performance, but to achieve this with...

meaningful affective and emotional connection between performers...

...and with a sense of

immediacy,

liveness

or embodied presence

... being produced for both

performer and audience.

Quoting Steve Dixon, researcher and practitioner

Elena Pérez describes:

'From a theatre and performance perspective, mere juxtaposition does not qualify for telematic performance to be satisfactory. He [Dixon] claims that "telematic works too commonly suspect that the simple presence of these remote, virtual bodies is considered to be enough, since the magic of technology is there for all to see". In his view, the juxtapositions need to be meaningful rather than separated and arbitrary.'

(Pérez, E. "Meaningful connections: Exploring the uses of telematic technology in performance." Liminalities: A Journal of Performance Studies 2014, 10 (2))

These new virtual dynamics do not eliminate

but complexify the embodied phenomenologies

of dance practice.

'Telepresence and its tactile interventions in and through the screen space complicate the boundaries of our bodies, extend our corporeal agency and influence and blur the distinctions between physicality and virtuality'

(Paulson, K. Here/There: Telepresence, Touch and Art at the Interface. London: MIT Press, 2017, p.10.)

The choreographic work becomes instead a...

'performative, choreographic open installation' 
which, increasingly, only exists when activated by the viewer.

The choreographic installation can then start to seem more like an interactive game space than a stage space...

and the choreographer becomes instead a curator of a set of real and virtual connections and interactions, working between...

dancer,

digital artist,

dramaturge,

technological apparatus,

and audience,

to create a sense of meaningful presence.

In our research we suggest that, as evidenced by the take-up of the Microsoft Kinect camera in performance arts since $2010, \ldots$

... an important next step in accessible tools for telematic performance should be a more refined and accurate, yet affordable and easily useable motion capture system.

Many audiences are already accustomed to the kinds of interactive functionality and participatory experience that are associated with gaming (how to use a controller, how to use a menu)...

and online audiences have proven that they want to be able to have more agency within the work.

Through interdisciplinary collaborative projects such as ours, dance performers and choreographers will start to intuitively understand these new...

... technologies of sharing and developing, working towards an exciting digital future for the traditional performance arts.

Mavin Khoo, Creative Associate

at Akram Khan Company, describes...

"I was genuinely concerned that the presence of motion capture in my process would be problematic in generating a kind of emotive human ownership to the work.

That it would be replaced by a technological imprint and that this would be deliver a sensationalist element to the work instead of a poetic one.

I was excited when I started to discover the opposite."

"Being made to creatively work differently is always a good thing. As a choreographer, one is always concerned about generating movement vocabulary first.

For me, it has always been a more internal space that I have had to engage with to articulate my body organically.

In this instance, I am reliant on observation.

It allows for a kind of objectivity to take hold in choices you make, particularly in relation to the body in time and space."

"It's an entirely new way of working for me and that has really been exciting.

It has been creatively challenging in the most positive sense, pushing those buttons to think differently and to create different movement"

Melissa Quek, head of dance at LASALLE, speaks to how the different graphic visualisations of the motion data affected her expression

"The experience fulfilled many of the things I was interested in

- for instance, how would I respond to the image, to come up with a new vocabulary of movement based on the abilities of the motion capture suit."

"One of the things that I thought about was how some of the sketches allowed me to focus better on the other dancer. 
Some created a good visual representation of the spatial relationship which made it easier to focus on my interaction with the other body

- they quite literally draw the link, and that was helpful."

"Others were fun and interesting to play with exactly because they were abstract. I felt like I was painting with my body in the space.

With each of the sketches I would move differently because of what the sketch emphasises or allows to happen."

"What is exciting is that, in the past, you would collaborate with a digital artist but they alone would create the visuals.

But if the dancer better understands the parameters of what the artist is doing then their movements are more directly designing the sketches that result,

and the visualisation can better support what the dancer is doing.

For instance, they can discuss what movement is being explored, what the data points are, how they relate to what is being visualised, and what the effect of manipulating those variables could be.

This could really improve the quality of this kind of collaboration."

Dr. Daniel Strutt (Goldsmiths, University of London)

Andreas Schlegel (LASALLE College of the Arts, Singapore)

Neal Coghlan (Studio Aszyk)

Clemence Debaig (Goldsmiths)

Youhong 'Friendred' Peng (Goldsmiths)

\section{COMPETING INTERESTS}

The authors have no competing interests to declare.

\section{AUTHOR AFFILIATIONS}

Daniel Strutt (D) orcid.org/0000-0001-5169-1145

Goldsmiths, University of London, UK

\section{Andreas Schlegel}

LASALLE College of the Arts, SG

\section{Neal Coghlan}

Studio Aszyk, UK

\section{Clemence Debaig}

Goldsmiths, University of London, UK

\section{Youhong 'Friendred' Peng}

Goldsmiths, University of London, UK
TO CITE THIS ARTICLE:

Strutt, D, Schlegel, A, Coghlan, N, Debaig, C and 'Friendred' Peng, Y. 2021. New Telematic Technologies for Remote Creation, Rehearsal and Performance of Choreographic Work. Journal of Embodied Research, 4(2): 4 (14:57). DOI: https://doi. org/10.16995/jer.82

Submitted: 06 November 2020 Accepted: 24 July 2021 Published: 11 October 2021

COPYRIGHT:

(C) 2021 The Author(s). This is an open-access article distributed under the terms of the Attribution-NonCommercialNoDerivatives 4.0 International License (CC BY-NC-ND 4.0), which permits unrestricted use, distribution, and reproduction in any medium, provided the original author and source are credited. See https:// creativecommons.org/licenses/ by-nc-nd/4.0/.

Journal of Embodied Research is a peer-reviewed open access journal published by Open Library of Humanities. 